\title{
ASSOCIATION BETWEEN METABOLIC SYNDROME AND DISABILITY DUE TO LOW BACK PAIN AMONG CARE WORKERS
}

YAMATO TSUBOI ${ }^{1}$, YUYA UEDA ${ }^{1,2}$, TAIKI SUGIMOTO ${ }^{1,3,4}$, FUMIHIRO NARUSE $^{5}$, and REI ONO ${ }^{1}$

${ }^{1}$ Kobe University Graduate School of Health Sciences, Kobe, Japan

Department of Community Health Sciences

${ }^{2}$ Kobe University Hospital, Kobe, Japan

Division of Rehabilitation Medicine

${ }^{3}$ National Center for Geriatrics and Gerontology, Obu, Japan

Center for Comprehensive Care and Research on Memory Disorders

${ }^{4}$ National Center for Geriatrics and Gerontology, Obu, Japan

Medical Genome Center

${ }^{5}$ eveRehab Inc., Kyoto, Japan

\begin{abstract}
Objectives: To elucidate the association between metabolic syndrome (MetS) and disability due to low back pain (LBP) among care workers. Material and Methods: This cross-sectional study enrolled 656 care workers having experienced LBP in the year prior to the year of this study. The Roland-Morris Disability questionnaire (RDQ) and self-reported questionnaires regarding LBP, fear of movement, depressive symptom, psychosocial factors, intensity of pain, and duration of pain were administered, and a medical examination was performed. Metabolic syndrome was defined according to the international definition agreed in 2009. Out of the 656 care workers, we included 316 care workers (response rate: $48.2 \%$ ) who had fully completed the questionnaires as the study sample (males: $13.6 \%$, median age $=51$ years old, range: $35-74$ years old). To examine the association between MetS and the level of disability due to LBP, we used the Poisson regression analysis and estimated crude and adjusted prevalence ratios (PR). Results: Out of the 316 care workers, $52(16.5 \%)$ were diagnosed as having MetS. Metabolic syndrome was significantly associated with the RDQ score (adjusted PR: 1.57, 95\% confidence interval (CI): 1.17-2.11) after adjusting for covariates, such as age, sex, fear of movement, job demands, social support, intensity of pain, and duration of pain. Conclusions: This study showed that MetS was independently associated with disability due to LBP among care workers. A multidisciplinary intervention taking MetS into consideration may be an effective way to reduce disability due to LBP in people with both LBP and MetS. Int J Occup Med Environ Health 2018;31(2):165-172
\end{abstract}

Key words:

Metabolic syndrome, Disability, Low back pain, Healthcare workers, Cross-sectional studies, Epidemiological studies

Received: Received: April 27, 2016. Accepted: December 4, 2016.

Corresponding author: R. Ono, Kobe University Graduate School of Health Sciences, Department of Community Health Sciences, 7-10-2 Tomogaoka, Suma-ward, 654-0142 Kobe, Japan (e-mail: ono@phoenix.kobe-u.ac.jp). 


\section{INTRODUCTION}

Low back pain (LBP) is a serious and common health problem among the working population. In Japan, LBP accounted for $62 \%$ of sick leaves longer than 4 days [1]. It has been particularly prevalent among care workers [2], with $19 \%$ of work-related LBP in Japan occurring among nursing home employees [1]. It often results in disability that affects daily living, leading to not only a decline in quality of life but also to a greater need for medical attention [3], thus creating a serious socioeconomic burden [4]. A good understanding of the potential risk factors for disability due to LBP is therefore essential for reducing the level of disability, improving quality of life and reducing the socioeconomic burden.

Disability due to LBP has been shown to be attributed to physical workload such as manual patient handling and psychosocial factors among care workers [5]. Previous studies showed that age, intensity of pain and duration of pain were significantly associated with disability due to LBP [6-8], as have fear of movement, depressive symptom and psychosocial factors [9-11]. In addition, a recent study of elderly women reported that the prevalence of LBP was significantly higher in a group with metabolic syndrome (MetS) than in the non-MetS group [12]. Metabolic syndrome is a cluster of symptoms, including central obesity, dyslipidaemia, hyperglycaemia and hypertension, which could be improved and prevented by modifying lifestyle factors such as diet and physical activity [13].

Thus, MetS may also lead to the exacerbation of disability due to LBP. However, no study has investigated this as yet. The purpose of this study has therefore been to investigate a potential association between MetS and disability among care workers with LBP. As care work presents with high prevalence of LBP, clarification of this relationship will help establish a more efficient approach towards LBP.

\section{MATERIAL AND METHODS}

\section{Study populations}

A cross-sectional survey was conducted from January 2014 to March 2014. We distributed self-reported questionnaires to 954 care workers employed by a Japanese company providing senior care services and performed their medical examination. We included 656 care workers $(68.8 \%)$ who had experienced LBP in the year prior to this study.

Ethical approval for this study was given by the Ethics Committee of Kobe University Graduate School of Health Sciences. By completing the questionnaires, the participants indicated their consent to participation. The protocol number of approval of this study is 336-1.

\section{Measurements}

Data on demographics and health status was collected from the results of the medical examination. Self-reported questionnaires were designed to collect information on the level of disability due to LBP, the details of the LBP, MetS, physical workload, fear of movement, depressive symptom, and psychosocial factors.

A Japanese version of the Roland-Morris Disability Questionnaire (RDQ) [14] was used for assessing disability in those having experienced LBP in the previous year. The RDQ is a validated and reliable instrument for assessing disability due to LBP [14]. It includes 20 items concerning limitations due to LBP in different daily life activities and 4 items concerning pain, sleep, appetite and emotional functions. Each item is scored either 0 or 1 , with all the scores summed to a total between 0 and 24 (higher score indicate greater limitations).

A further questionnaire evaluated details of LBP, such as intensity (no pain, little pain, normal pain, severe pain or very severe pain) and duration $(<1$ week, 1 week to 1 month, 1-3 months, $>3$ months).

To diagnose MetS, we used the definition agreed upon at an international meeting in 2009 [13]. This defini- 
tion basically follows the standard established by the National Cholesterol Education Program Adult Treatment Panel III; however, for waist circumference, it uses the standard of the International Diabetes Federation. According to this definition, having any 3 of the following 5 abnormal findings results in a diagnosis of MetS:

- waist circumference: $\geq 90 \mathrm{~cm}$ for men and $\geq 80 \mathrm{~cm}$ for women,

- blood pressure (BP): systolic BP $\geq 130 \mathrm{~mm} \mathrm{Hg}$ or diastolic $\mathrm{BP} \geq 85 \mathrm{~mm} \mathrm{Hg}$ (or antihypertensive drug treatment in a patient with a history of hypertension),

- triglyceride: $\geq 150 \mathrm{mg} / \mathrm{dl}$ (or drug treatment for elevated triglycerides),

- high density lipoprotein cholesterol (HDL-c): male $\leq 40 \mathrm{mg} / \mathrm{dl}$, female $\leq 50 \mathrm{mg} / \mathrm{dl}$ (or drug treatment for reduced HDL-c),

- fasting glucose: $\geq 100 \mathrm{mg} / \mathrm{dl}$ (or drug treatment for elevated glucose).

Physical workload was estimated with a physical workload index developed and validated by Hollmann [15]. This index includes unfavorable postures of the body during work (bending, twisting, kneeling or squatting) as well as handling heavy loads. Fourteen items are used for describing the postures: 3 describe postures of the trunk (strongly inclined, twisted, laterally bent), 2 describe positions of the arms (1 arm above shoulder height, 2 arms above shoulder height), 3 describe the position of the legs (squatting, kneeling on one or both knees, walking or moving), 3 describe lifting weights with the trunk upright and 3 describe the weight lifted with the trunk inclined by $60^{\circ}(<10 \mathrm{~kg}, 10-20 \mathrm{~kg}$, $>20 \mathrm{~kg}$ ). Each item is presented as a pictogram and has a 5-point Likert scale ranging from "never" to "very often." These values were aggregated to a single value between 0 and 52.56, which was an estimate of the total physical workload (with higher score indicating a greater physical workload).
To assess the fear of movement, we used a Japanese version of the 11-item Tampa Scale of Kinesiophobia (TSK) [16]. Each item was scored on a 4-point Likert scale (with higher score indicating more severe fear of movement).

Depressive symptom was assessed using a Japanese version of the Center for Epidemiologic Studies Depression Scale (CES-D) [17], which comprises 10 items, each scored on a 4-point Likert scale. Therefore, the total score ranges between 0 and 30 , with a score of 10 or greater indicating a clinically relevant depressive symptom.

We used a Japanese version of the Job Content Questionnaire (JCQ) to assess psychosocial characteristics of each participant's job [18]. To assure confidentiality, we ensured that the answers were only seen by the researchers when the self-report questionnaires were collected. The JCQ consists of 3 subscales: job demands, job control and social support. Job demands (range: 12-48) includes 5 items; Job control (range: 24-96) comprises 2 further subscales (skill discretion (6 items) and decision authority (3 items)); and Social support (range: 8-32) also comprises 2 subscales (supervisor support (4 items) and co-worker support (4 items)). All items are scored on a 4-point Likert scale.

\section{Statistical analysis}

Distributions of demographic data were compared between the MetS group and the non-MetS group using the Mann-Whitney U test or $\mathrm{Chi}^{2}$ test.

We performed the univariate and multiple Poisson regression analysis with robust variance to investigate the association of MetS and covariates with RDQ. Age, sex and the variables shown to be statistically significant $(p<0.05)$ in the univariate Poisson regression analysis were selected as covariates. Crude and adjusted prevalence ratios (PR) with $95 \%$ confidence intervals (CI) were computed. All statistical analyses were performed using Stata v. 13.1. The p-values less than 0.05 were considered statistically significant. 


\section{RESULTS}

Out of 656 care workers who had experienced LBP in the year prior to this study, we included 316 care workers (response rate: $48.2 \%$ ) who had fully completed the questionnaires as the study sample (male: $13.6 \%$, median age $=51$ years, range: $35-74$ years). Fifty-two (16.5\%) participants were diagnosed with MetS. The median RDQ score was 2 (range: 0-20).

The Table 1 shows the comparison of characteristics between the MetS and the non-MetS group. The MetS group was significantly older and had significantly higher body mass index (BMI), waist circumference, systolic and diastolic blood pressure, triglycerides, fasting glucose and lower HDL-c than the non-MetS group.

In the univariate Poisson regression analysis, the RDQ scores were significantly associated with $\mathrm{MetS}(\mathrm{PR}=1.63$ (95\% CI: 1.19-2.22)), TSK score (PR = 1.07 (95\% CI: 1.05-1.10)), job demands (PR = 1.03 (95\% CI: 1.00-1.06)), social support ( $\mathrm{PR}=0.95$ (95\% CI: 0.92-0.99)), intensity of pain (PR $=1.55$ (95\% CI: 1.39-1.74)), and duration of pain (PR $=1.29$ (95\% CI: 1.15-1.44)). In the multiple Poisson regression analysis, MetS was significantly associated with RDQ score after adjusting for the covariates (Table 2). Significant associations with RDQ score were also found

Table 1. Characteristics of care workers in the study of association between metabolic syndrome (MetS) and disability due to low back pain

\begin{tabular}{lccr}
\hline & \multicolumn{2}{c}{$\begin{array}{c}\text { Respondents } \\
\text { Characteristics }\end{array}$} & p \\
\cline { 2 - 3 } & with MetS & without MetS & \\
& $(\mathrm{N}=52)$ & $(\mathrm{N}=264)$ & \\
\hline Age [years] (Me (min.-max)) & $56(35-73)$ & $50(35-74)$ & $<0.05$ \\
Sex (males) [n (\%)] & $8(15.4)$ & $35(13.3)$ & 0.68 \\
Body mass index (BMI) [kg/m²] (Me (min.-max)) & $26.0(18.7-37.4)$ & $21.1(15.3-33.6)$ & $<0.05$ \\
Waist circumference [cm] (Me (min.-max)) & $91.1(71-117.2)$ & $77.9(52.0-111.8)$ & $<0.05$ \\
Blood pressure [mm Hg] (Me (min.-max)) & & & \\
$\quad$ systolic & $138(108-170)$ & $117(78-176)$ & $<0.05$ \\
$\quad$ diastolic & $82(52-114)$ & $70(40-106)$ & $<0.05$ \\
Triglycerides [mg/dl] (Me (min.-max)) & $118(39-533)$ & $70(28-127)$ & $<0.05$ \\
High density lipoprotein cholesterol (HDL-c) [mg/dl] (Me (min.-max)) & $55(33-101)$ & $73(40-408)$ & $<0.05$ \\
Fasting glucose [mg/dl] (Me (min.-max)) & $101(77-248)$ & $87(68-201)$ & $<0.05$ \\
Smoking status (current smokers) [n (\%)] & $8(15.4)$ & $74(28.0)$ & 0.06 \\
Depressive symptoms [n (\%)] & $7(13.5)$ & $50(18.9)$ & 0.35 \\
Tampa Scale for Kinesiophobia [16] (Me (min.-max)) & $23(12-34)$ & $22(11-40)$ & 0.95 \\
Job Content Questionnaire (JCQ) & & & \\
Job demands (Me (min.-max)) & $31(24-46)$ & $32(18-48)$ & 0.61 \\
Job control (Me (min.-max)) & $64(48-90)$ & $66(34-92)$ & 0.31 \\
Social support (Me (min.-max)) & $23(12-32)$ & $24(9-32)$ & 0.10 \\
Physical work load (Me (min.-max)) & $25.4(6.2-56.2)$ & $23.0(1.3-56.2)$ & 0.21 \\
\hline
\end{tabular}

Me - median; min. - minimal value; max - maximal value. 
Table 2. Poisson regression analysis for estimating prevalence ratio (PR) of disability due to low back pain (LBP) of care workers with and without metabolic syndrome (MetS)

\begin{tabular}{lcccc}
\hline \multirow{2}{*}{$\begin{array}{c}\text { Respondents } \\
(\mathrm{N}=316)\end{array}$} & \multicolumn{2}{c}{ Univariate analysis } & \multicolumn{2}{c}{ Multiple analysis } \\
\cline { 2 - 5 } & crude PR & $95 \% \mathrm{CI}$ & adjusted $\mathrm{PR}^{\mathrm{a}}$ & $95 \% \mathrm{CI}$ \\
\hline Without MetS $(\mathrm{N}=264)$ & ref. & ref. & \\
With MetS $(\mathrm{N}=52)$ & 1.63 & $1.19-2.22^{*}$ & 1.57 & $1.17-2.11^{*}$ \\
\hline
\end{tabular}

CI - confidence interval.

${ }^{a}$ The multiple analysis was adjusted for age, sex and factors associated with disability for LBP including fear of movement, job demands, social support, intensity of pain and duration of pain in the univariate Poisson analysis.

$* \mathrm{p}<0.05$.

for TSK score (PR = 1.05 (95\% CI: 1.02-1.08)), intensity of pain (PR $=1.44$ (95\% CI: 1.27-1.62)) and duration of pain $(\mathrm{PR}=1.14$ (95\% CI: 1.02-1.28)).

\section{DISCUSSION}

The purpose of this study has been to investigate the association between MetS and disability due to LBP among care workers. The results showed that MetS was significantly associated with disability due to LBP and that this association was independent of the other covariates, such as age, sex, fear of movement, job demands, social support, intensity of pain and duration of pain. In addition to MetS, fear of movement, intensity of pain, and duration of pain were also associated with the disability due to LBP in the multiple Poisson regression analysis. These results were consistent with previous studies [6-8].

This is the first study to show an independent association between MetS and disability due to LBP in care workers. There are several possible explanations for the association. Metabolic syndrome consists of central obesity, dyslipidaemia, hyperglycaemia and hypertension. Central obesity results in greater torque and compression loads on the lumbar spine than general obesity [19]. Furthermore, recent studies have reported that people with MetS also carry systemic chronic inflammation because adipokines are abnormally generated from their adipose tissue [20], and that chronic inflammation can cause joint degenera- tion and osteoarthritis [21,22]. Another study found that there were high levels of inflammatory cytokines in facet joint cartilage and the synovium in people with degenerative lumbar spinal disorders [23]. Thus, central obesity and chronic inflammation can result in high lumbar spine loads in people with both LBP and MetS, and this may have exacerbated the level of disability due to LBP.

All subjects in this study were care workers. Care workers are frequently required to undertake manual handling as part of their work such as, transferring, lifting and repositioning in their works. Biomechanical investigations have confirmed that such manual handling generates high spinal stresses $[24,25]$. From these findings, it was considered that higher lumbar spine loads during manual handling are more likely to be experienced by care workers with MetS than by those without, and also that this would result in an exacerbation of disability due to LBP.

Our results have potential implications for the most appropriate approach to be taken for people with both LBP and MetS. According to the biopsychosocial model proposed by Waddell, interventions for LBP should not be limited to addressing biological problems but should take all dimensions into consideration [26]. A recent systematic review revealed that multidisciplinary interventions were more effective than normal care and physical treatment in relieving pain and disability among people with chronic LBP [27]. Some randomized controlled trials have shown 
that multidisciplinary interventions consisting of physical exercise with psychological and ergonomic approaches, such as evaluation and adjustment of the workplace, improved pain and disability among people with chronic LBP in comparison with the usual physical therapy [28,29].

In this study, we have found an association between MetS and the level of disability due to LBP. For MetS to resolve, a combination of physical exercise and nutritional therapy is essential. The American Diabetes Association and the National Cholesterol Education Program Adult Treatment Panel III recommend therapeutic lifestyle changes, including a reduced intake of saturated fats and cholesterol and an increase in physical activity [30]. Therefore, adding an approach for addressing MetS to the conventional approach for LBP is effective for reducing disability due to LBP among people with both LBP and MetS.

This study has had several limitations that should be considered. First, we did not examine any image diagnoses and inflammation markers; therefore, physiological and biomechanical factors could not be covered in this study. We should evaluate these factors in further studies. Secondly, although our results were adjusted for sex, the majority of participants in this study were female. Some studies reported that a sex difference existed in disability due to musculoskeletal pain including LBP; female had greater pain-related disability than male [31-33]. Thus, caution should be taken in generalization of the results. Thirdly, this study has had a cross-sectional design. Therefore, as a causal relationship between MetS and disability due to LBP cannot be established, a longitudinal study should be performed in the future.

\section{CONCLUSIONS}

This study has shown that MetS is independently associated with disability due to LBP among care workers. A multidisciplinary intervention adding an approach for MetS may be an effective way to reduce disability due to LBP in people with both LBP and MetS.

\section{ACKNOWLEDGMENTS}

We would like to thank all study participants for taking their time and willingness to response questionnaires. We also gratefully acknowledge staffs for distribution and collection of questionnaires.

\section{REFERENCES}

1. Japan Ministry of Health, Labour and Welfare. The occurrence of work-related diseases in 2011 [Internet]. Tokyo: The ministry [cited 2016 Sep 30]. Available from: http://www.mhlw.go.jp/bunya/roudoukijun/anzeneisei11/h23.html. Japanese.

2. Lorusso A, Bruno S, LAbbate N. A review of low back pain and musculoskeletal disorders among Italian nursing personnel. Ind Health. 2007;45(5):637-44, https://doi.org/10.2486/ indhealth.45.637.

3. Ferreira ML, Machado G, Latimer J, Maher C, Ferreira PH, Smeets RJ. Factors defining care-seeking in low back pain - A meta-analysis of population based surveys. Eur J Pain. 2010;14(7):747.e1-7, https://doi.org/10.1016/j.ejpain.20 09.11.005.

4. Itoh H, Kitamura F, Yokoyama K. Estimates of annual medical costs of work-related low back pain in Japan. Ind Health. 2013;51(5):524-9, https://doi.org/10.2486/indhealth. 2013-0042.

5. Eriksen W, Bruusgaard D, Knardahl S. Work factors as predictors of intense or disabling low back pain; a prospective study of nurses' aides. Occup Environ Med. 2004;61(5): 398-404, https://doi.org/10.1136/oem.2003.008482.

6. Covinsky KE, Lindquist K, Dunlop DD, Yelin E. Pain, functional limitations, and aging. J Am Geriatr Soc. 2009;57(9):1556-61, https://doi.org/10.1111/j.1532-5415.2009. 02388.x.

7. Gheldof EL, Vinck J, van den Bussche E, Vlaeyen JW, Hidding A, Crombez G. Pain and pain-related fear are associated with functional and social disability in an occupational setting: Evidence of mediation by pain-related fear. Eur J Pain. 2006;10(6):513-25, https://doi.org/10.1016/j.ejpain. 2005.07.005. 
8. Kovacs FM, Abraira V, Zamora J, Fernández C; Spanish Back Pain Research Network. The transition from acute to subacute and chronic low back pain: A study based on determinants of quality of life and prediction of chronic disability. Spine (Phila Pa 1976). 2005;30(15):1786-92, https://doi. org/10.1097/01.brs.0000172159.47152.dc.

9. Crombez G, Vlaeyen JW, Heuts PH, Lysens R. Pain-related fear is more disabling than pain itself: Evidence on the role of pain-related fear in chronic back pain disability. Pain. 1999;80(1-2):329-39, https://doi.org/10.1016/S03043959(98)00229-2.

10. Matsudaira K, Konishi H, Miyoshi K, Isomura T, Inuzuka K. Potential risk factors of persistent low back pain developing from mild low back pain in urban Japanese workers. PLoS One. 2014;9(4):e93924, https://doi.org/10.1371/ journal.pone.0093924.

11. Waddell G, Newton M, Henderson I, Somerville D, Main CJ. A Fear-Avoidance Beliefs Questionnaire (FABQ) and the role of fear-avoidance beliefs in chronic low back pain and disability. Pain. 1993;52(2):157-68, https://doi.org/10.1016/ 0304-3959(93)90127-B.

12. Ono R, Yamazaki S, Takegami M, Otani K, Sekiguchi M, Onishi $\mathrm{Y}$, et al. Gender difference in association between low back pain and metabolic syndrome: Locomotive syndrome and health outcome in Aizu cohort study (LOHAS). Spine (Phila Pa 1976). 2012;37(13):1130-7, https://doi.org/ 10.1097/BRS.0b013e31824231b8.

13. Alberti KG, Eckel RH, Grundy SM, Zimmet PZ, Cleeman JI, Donato KA, et al. Harmonizing the metabolic syndrome: A joint interim statement of the International Diabetes Federation Task Force on Epidemiology and Prevention; National Heart, Lung, and Blood Institute; American Heart Association; World Heart Federation; International Atherosclerosis Society; and International Association for the Study of Obesity. Circulation. 2009;120(16):1640-5, https://doi.org/10.1161/CIRCULATIONAHA.109.192644.

14. Suzukamo Y, Fukuhara S, Kikuchi S, Konno S, Roland M, Iwamoto $\mathrm{Y}$, et al. Validation of the Japanese version of the Roland-Morris Disability Questionnaire. J Orthop Sci. 2003;8(4):543-8, https://doi.org/10.1007/s00776-003-0679-x.

15. Hollmann S, Klimmer F, Schmidt KH, Kylian H. Validation of a questionnaire for assessing physical work load. Scand J Work Environ Health. 1999;25(2):105-14, https://doi.org/ 10.5271/sjweh.412.

16. Kikuchi N, Matsudaira K, Sawada T, Oka H. Psychometric properties of the Japanese version of the Tampa Scale for Kinesiophobia (TSK-J) in patients with whiplash neck injury pain and/or low back pain. J Orthop Sci. 2015;20(6): 985-92, https://doi.org/10.1007/s00776-015-0751-3.

17. Shima S, Shikano T, Kitamura T, Asai M. [Development of a new self-reported depression scale]. Seishin Igaku. 1985;27:717-23. Japanese.

18. Kawakami N, Kobayashi F, Araki S, Haratani T, Furui H. Assessment of job stress dimensions based on the Job Demands-Control model of employees of telecommunication and electric power companies in Japan: Reliability and validity of the Japanese version of Job Content Questionnaire. Int J Behav Med. 1995;2(4):358-75, https://doi.org/10.1207/ s15327558ijbm0204_5.

19. Pryce R, Kriellaars D. Body segment inertial parameters and low back load in individuals with central adiposity. J Biomech. 2014;47(12):3080-6, https://doi.org/10.1016/ j.jbiomech.2014.06.038.

20. Bays HE, González-Campoy JM, Henry RR, Bergman DA, Kitabchi AE, Schorr AB, et al. Is adiposopathy (sick fat) an endocrine disease? Int J Clin Pract. 2008;62(10):1474-83, https://doi.org/10.1111/j.1742-1241.2008.01848.x.

21. Berenbaum F, Eymard F, Houard X. Osteoarthritis, inflammation and obesity. Curr Opin Rheumatol. 2013;25(1): 114-8, https://doi.org/10.1097/BOR.0b013e32835a9414.

22. Goldring MB, Otero M. Inflammation in osteoarthritis. Curr Opin Rheumatol. 2011;23(5):471-8, https://doi.org/10. 1097/BOR.0b013e328349c2b1.

23. Igarashi A, Kikuchi S, Konno S, Olmarker K. Inflammatory cytokines released from the facet joint tissue in degenerative lumbar spinal disorders. Spine (Phila Pa 1976). 
2004;29(19):2091-5, https://doi.org/10.1097/01.brs.0000141 265.55411.30.

24. Garg A, Owen BD, Carlson B. An ergonomic evaluation of nursing assistants' job in a nursing home. Ergonomics. 1992;35(9):979-95, https://doi.org/10.1080/0014013920 8967377.

25. Gagnon M, Sicard C, Sirois JP. Evaluation of forces on the lumbo-sacral joint and assessment of work and energy transfers in nursing aides lifting patients. Ergonomics. 1986; 29(3):407-21, https://doi.org/10.1080/00140138608968274.

26. Waddell G. Biopsychosocial analysis of low back pain. Baillieres Clin Rheumatol. 1992;6(3):523-57, https://doi. org/10.1016/S0950-3579(05)80126-8.

27. Kamper SJ, Apeldoorn AT, Chiarotto A, Smeets RJ, Ostelo RW, Guzman J, et al. Multidisciplinary biopsychosocial rehabilitation for chronic low back pain: Cochrane systematic review and meta-analysis. BMJ. 2015;350:h444, https:// doi.org/10.1136/bmj.h444.

28. Henchoz Y, de Goumoëns P, So AK, Paillex R. Functional multidisciplinary rehabilitation versus outpatient physiotherapy for non specific low back pain: Randomized controlled trial. Swiss Med Wkly. 2010;140:w13133, https:/doi. org/10.4414/smw.2010.13133.

29. Kääpä EH, Frantsi K, Sarna S, Malmivaara A. Multidisciplinary group rehabilitation versus individual physiotherapy for chronic nonspecific low back pain: A randomized trial. Spine (Phila Pa 1976). 2006;31(4):371-6, https://doi.org/ 10.1097/01.brs.0000200104.90759.8c.

30. Expert Panel on Detection Evaluation, and Treatment of High Blood Cholesterol in Adults. Executive summary of The Third Report of The National Cholesterol Education Program (NCEP) Expert Panel on Detection, Evaluation, and Treatment of High Blood Cholesterol in Adults (Adult Treatment Panel III). JAMA. 2001;285(19):2486-97, https:// doi.org/10.1001/jama.285.19.2486.

31. Greenspan JD, Craft RM, LeResche L, Arendt-Nielsen L, Berkley KJ, Fillingim RB, et al. Studying sex and gender differences in pain and analgesia: A consensus report. Pain. 2007;132(Suppl 1):S26-45, https://doi.org/10.1016/j.pain.20 07.10.014.

32. Müllersdorf M, Söderback I. The actual state of the effects, treatment and incidence of disabling pain in a gender perspective - A Swedish study. Disabil Rehabil. 2000;22(18): 840-54, https://doi.org/10.1080/09638280050207893.

33. Enthoven P, Skargren E, Carstensen J, Oberg B. Predictive factors for 1-year and 5-year outcome for disability in a working population of patients with low back pain treated in primary care. Pain. 2006;122(1-2):137-44, https://doi. org/10.1016/j.pain.2006.01.022.

This work is available in Open Access model and licensed under a Creative Commons Attribution-NonCommercial 3.0 Poland License - http://creativecommons.org/ licenses/by-nc/3.0/pl/deed.en. 